\title{
Sufrimiento humano y representación de víctimas. El caso de Chungui en la posguerra peruana
}

Souffrance humaine et représentation des victimes. Le cas de Chungui dans l'après-guerre au Pérou

Human Suffering and the Representation of Victims: The case of Chungui in post-war Peru

\section{Nathalie Koc-Menard}

\section{OpenEdition}

\section{Journals}

Edición electrónica

URL: http://journals.openedition.org/bifea/5189

DOI: $10.4000 /$ bifea.5189

ISSN: 2076-5827

\section{Editor}

Institut Français d'Études Andines

\section{Edición impresa}

Fecha de publicación: 1 agosto 2014

Paginación: 209-226

ISSN: 0303-7495

\section{Referencia electrónica}

Nathalie Koc-Menard, "Sufrimiento humano y representación de víctimas. El caso de Chungui en la posguerra peruana », Bulletin de l'Institut français d'études andines [En línea], 43 (2) | 2014, Publicado el 08 agosto 2014, consultado el 10 diciembre 2020. URL : http://journals.openedition.org/bifea/5189 ; DOI : https://doi.org/10.4000/bifea.5189

\section{(c) $(1) \odot$}

Les contenus du Bulletin de l'Institut français d'études andines sont mis à disposition selon les termes de la licence Creative Commons Attribution - Pas d'Utilisation Commerciale - Pas de Modification 4.0 International. 


\title{
Sufrimiento humano y representación de víctimas. El caso de Chungui en la posguerra peruana
}

\author{
Nathalie Koc-Menard*
}

\begin{abstract}
Resumen
Enfocándose en el distrito de Chungui, en la región de Ayacucho-Perú, este trabajo busca analizar cómo las representaciones del sufrimiento humano han sido producidas después del conflicto armado interno. Estas representaciones muchas veces corren el peligro de tergiversarse reduciendo los Andes a un lugar habitado por salvajes e ignorantes, si como académicos no fuéramos conscientes de las relaciones jerárquicas en las cuales nos encontramos. Es así que el testigo humanitario en el cual nos convertimos cuando trabajamos con comunidades de posguerra, asume el rol de alguien que habla por y no con las víctimas reproduciendo las jerarquías de poder y dominación que originalmente intentábamos combatir.
\end{abstract}

Palabras clave: sufrimiento humano, violencia, testigo humanitario, Chungui, representación

\section{Souffrance humaine et représentation des victimes. Le cas de Chungui dans I'après-guerre au Pérou}

\section{Résumé}

Centré sur le district de Chungui, dans les Andes péruviennes d'Ayacucho, ce travail analyse les représentations sur la souffrance humaine qui ont été produites au lendemain de la guerre interne. Ces représentations peuvent déformer la réalité en réduisant les Andes à un espace habité par des êtres sauvages et ignorants, comme si nous, universitaires, n'étions pas conscients des relations hiérarchiques dans lesquelles nous sommes intégrés. Pour cette raison, le témoin humanitaire que nous devenons en travaillant avec des communautés d'après-guerre finit par assumer le rôle de celui qui parle pour et

* Doctora en Antropología Social. Docente en la Pontificia Universidad Católica del Perú (PUCP). E-mail: nkocmenard@gmail.com 
non avec les victimes, au risque de reproduire les hiérarchies de pouvoir et de domination que nous cherchions précisément à combattre.

Mots-clés : souffrance humaine, violence, témoin humanitaire, représentation, Chungui

\title{
Human Suffering and the Representation of Victims: The case of Chungui in post-war Peru
}

\begin{abstract}
Focusing on the district of Chungui in the Peruvian Andean region of Ayacucho, this paper analyzes how, in the aftermath of the Peruvian armed internal conflict, representations of human suffering have been produced. These representations could result in distortions reducing the Andes to a space inhabited by savages and ignorant people, if as scholars, we are not aware of the hierarchical relationships in which we are embedded. Therefore, the humanitarian witness that we become when we work with post-war communities must assume the role of someone who speaks for and not with war victims. This will allow us to avoid reproducing the hierarchies of power and domination we originally intended to fight.
\end{abstract}

Keywords: human suffering, violence, humanitarian witness, representation, Chungui

En el año 2002 llegué por primera vez al distrito de Chungui en Ayacucho, como investigadora de la Comisión de la Verdad y Reconciliación (CVR) y como una de los responsables del equipo que contextualizaba los testimonios presentados ante la CVR en esta sede. Desde entonces, interesada por su historia y conflictos, Chungui se convirtió en el lugar de mi investigación.

El objetivo final de este artículo es analizar cómo los académicos han representado y representan el sufrimiento humano producido por el conflicto armado interno. Una labor que debe reconocerse como una encrucijada, pues al mismo tiempo que se quiere denunciar el dolor y el sufrimiento que la violencia produce en las poblaciones, se termina despojando a las víctimas de voz y protagonismo en sus propias historias. En ningún momento este trabajo intenta dar una fórmula que se considere superior o una lección moral de cómo debe representarse a las víctimas del conflicto armado interno. Al contrario, la intención es reflexionar acerca de las diversas maneras de representar a las víctimas de la guerra y la importancia de pensar en cómo muchas veces estas retroalimentan las imágenes que se desea combatir, como la de víctimas pasivas y sin agencia política «atrapadas entre dos fuegos».

Para ello, se inicia esta reflexión con mi propia autocrítica académica. Durante mi trabajo como investigadora en la CVR, y en especial, al escribir reportes que luego formarían parte del Informe Final, no era consciente del poder que teníamos como académicos, el poder de dar voz a quienes consideramos históricamente ignorados y silenciados en la sociedad peruana. Lamentablemente en aquel momento no reconocí que mi trabajo en la CVR era político y que este no trataba de darle voz 
a la gente, cómo hablar por ellos. Este no sería un proyecto de empoderamiento inmediato. La CVR, y me incluyo entre ellos, se convirtió en un actor político que interpretó la guerra y denunció las violaciones contra los Derechos Humanos que se habían cometido, un trabajo que con todos los defectos que se les pueda encontrar hoy, era necesario hacer. Nos convertimos en intermediarios, en voceros y testigos humanitarios ${ }^{1}$ y no estábamos dándole voz a las comunidades afectadas por el conflicto armado interno, estábamos hablando por ellas ante una sociedad que aún las excluye y no las escucha. En aquel momento, no era consciente de ello, y no fue sino años después que empecé a entender que hablar por la gente y actuar como intermediario contribuye a reforzar la imagen de población excluida y silenciada que existe en la sociedad peruana. A pesar de las buenas intenciones que teníamos en la CVR, estábamos en una encrucijada, había que denunciar las atrocidades cometidas por los diversos actores del conflicto armado interno a pesar de que muchas veces silenciáramos a las poblaciones mismas (consciente y/o inconscientemente). En el plano discursivo se optó por hablar por ellos con nuestra voz y poder: la de la élite académica y política de la cual formamos parte. La falta de reconocimiento de mi propio poder al categorizar a la gente de las comunidades donde había trabajado como «marginal» y «olvidada», me impedían ver que el uso de estas categorías solo reproducen el discurso de sujetos marginados y excluidos que estábamos intentando combatir. Con esto no quiero decir que descubrí algo nuevo, sino que intento llamar la atención sobre la importancia que debemos darle a las categorías usadas para representar al otro, el poder implícito de estas, así como el de las representaciones y discursos que producimos, y por último cómo podemos reproducir las jerarquías y dominación, contra las cuales —se supone- estamos luchando. Pero también es esencial reconocer que en situaciones de guerra, estamos ante una encrucijada y muchas veces se opta por hablar por la gente porque es la manera más rápida y efectiva de llegar a quienes pueden ayudar.

En el año 20102, cuando escribí la primera versión de este artículo, consideraba que la academia peruana necesitaba tomar distancia de las conclusiones paradigmáticas del Informe Final de la CVR. Considero que nuestra responsabilidad como investigadores debe llevarnos a mirar con ojos críticos el Informe Final y los discursos que este ha originado, como el desarrollado sobre el sufrimiento de las víctimas durante el conflicto armado interno. Con ello no intento decir ni que la información producida ni los testimonios recogidos en el año 2002, y presentados en el Informe Final, no fueran auténticos, ni intento juzgar la decisión tomada por

1 Fassin \& Rechtman (2009) hablan de testigo humanitario. En este caso se utiliza vocero humanitario o vocero del sufrimiento humano. Este vocero, tal como lo definen dichos autores, siente el deber moral de transmitir los testimonios de sufrimiento y violencia de la gente con la finalidad de denunciar públicamente las atrocidades causadas durante la guerra. Lo problemático es que en la mayoría de casos el centro de la denuncia se produce modelando una narrativa de lo que el vocero humanitario considera importante y no necesariamente la historia original que los actores centrales quieren transmitir.

2 Este artículo está basado en un capítulo de mi tesis doctoral (Koc-Menard, 2011). 
los comisionados a quienes respeto. Por el contrario, este texto busca entender el Informe Final y a la CVR como el producto de un contexto político e histórico particular, en el cual ciertas afirmaciones no podían hacerse ${ }^{3}$.

Sin embargo, diez años después de la entrega del Informe Final, y luego de regresar al Perú, resultó estimulante encontrar investigadores interesados en analizar y cuestionar temas complejos y espinosos relacionados con el conflicto armado interno, como la deshumanización de los miembros de Sendero Luminoso y de las fuerzas del orden (FF. OO.)4. Además se inicia un debate sobre la categoría social de «víctima», una etiqueta que refuerza la imagen del poblador rural como un ser pasivo e ignorante, profundamente enraizada en el imaginario peruano: urbano, criollo y mestizo.

Este artículo no es una crítica destructiva al trabajo realizado por la CVR. Al contrario, se intenta ir más allá del Informe Final y reflexionar acerca de las representaciones del sufrimiento humano que han surgido en la posguerra peruana. En este nuevo escenario resulta importante incluir este tema porque, tal y como se ha presentado, el sufrimiento de las víctimas solo genera pena y una empatía pasajera, que asocia la violencia como parte natural de lugares excluidos y considerados «salvajes» del país, como los Andes.

La primera parte de este trabajo describe las comunidades de Chungui y Chapi. La segunda analiza la representación más importante sobre Chungui: el libro de Edilberto Jiménez (2009), comentado por Carlos Iván Degregori. Es importante reconocer que la partida de Carlos Iván es una gran pérdida para la academia peruana, y lo digo como su estudiante y colega pues trabajé con él en la CVR. Una persona íntegra y comprometida con quien me hubiese gustado muchísimo poder conversar y discutir este texto. Del mismo modo, E. Jiménez es un gran profesional, artista y amigo comprometido con los DD. HH. y creo que es admirable que luego de tantos años siga luchando, junto con los campesinos, por la justicia; además, el libro que publicaron juntos es un gran trabajo. Aunque este artículo solo trata un caso, es lo suficientemente relevante pues dicho libro se concentra en las representaciones del sufrimiento humano producidos en la posguerra. Finalmente, la tercera parte reflexiona acerca de cómo las representaciones del sufrimiento humano comparten una petición humanitaria de empatía superficial que solo reduce el distrito de Chungui a un espacio de extrema violencia y barbarie.

3 Por ejemplo, no se podía afirmar que la población de los Andes apoyó el inicio de Sendero Luminoso, por razones políticas. Era mucho mejor presentar víctimas y cuerpos sufrientes que producir un debate, a nivel nacional, del porqué los «Indios» habían creído en el proyecto de Sendero Luminoso.

4 Al usar FF. OO. en lugar de FF. AA. (Fuerzas Armadas) se busca incluir a los miembros de la policía que muchas veces quedan excluidos del análisis. 


\section{EL PROBLEMA: ¿CÓMO REPRESENTAR EL SUFRIMIENTO HUMANO CAUSADO POR LA GUERRA?}

Algunos especialistas (cf. Mehl, 1996) han afirmado que los medios de comunicación han logrado establecer una estrecha relación con sus interlocutores respecto a la desgracia humana, conforme a un «protocolo de compasión» que interactúa con el sufrimiento humano. Lo íntimo se muestra en público y es mostrado frecuentemente por los voceros humanitarios, quienes juegan un rol importante como testigos directos del sufrimiento. Las causas, el componente político, así como el contexto histórico de la guerra, son muchas veces simplificados para mostrarnos solo cuerpos sufrientes y adoloridos. En circunstancias como la sequía en el Cuerno de África, la televisión actúa como intermediario mostrando a niños famélicos y a los presentadores solicitando ayuda para ellos. En este contexto, las «víctimas» lejanas se vuelven próximas y la compleja realidad política queda reducida a una emotiva súplica por compasión (Fassin \& Rechtman, 2009: 194).

Para ser socialmente eficaz, la tarea de transformar la violencia y la opresión en sufrimiento debe comenzar propagando información. Cuando los testimonios de las víctimas de guerra se mezclan con datos que contextualizan el fenómeno social en un espacio y tiempo determinados, estos relatos pierden fuerza y empatía. Dentro de estas historias la prioridad la tienen las emociones sobre los datos concretos. El cuerpo sufriente resulta más importante que el contexto, la reflexión y el análisis (Fassin \& Rechtman, 2009: 202). Lo importante es diseminar un discurso único, que sea claro y simple, cuya realidad no pueda cuestionarse. Esta simplificación del discurso diseminado por el vocero humanitario deja fuera elementos cruciales, como el contexto histórico en los que este sufrimiento está anclado, el cual resulta indispensable para comprender las causas de la guerra.

En el caso de Chungui, los pobladores han mostrado constantemente su sufrimiento y han expuesto múltiples veces sus miserias en público. La repetición del mismo relato, mostrar el cuerpo herido afecta a las personas en cuanto son sujetos políticos. La imagen que ellas crean de sí mismas y de la manera en que son percibidas por otros, así como la traducción de esta realidad en términos políticos, se ve afectada por el hecho de que ellas se dan cuenta de que se las encasilla exclusivamente como víctimas y su identidad queda reducida a este aspecto (cf. Fassin \& Rechtman, 2009: 212).

Es importante resaltar que estas imágenes son comunes en situaciones de guerra y crisis humanitarias, pues pareciera ser esta la única posibilidad que tienen las víctimas de ser escuchadas: un discurso que resalta los traumas, las miserias y el sufrimiento vividos. He aquí la encrucijada frente a la cual nos encontramos quienes buscamos denunciar las atrocidades que se cometen en los conflictos armados. El discurso que siguió al Informe Final estuvo centrado sobre todo en visualizar el sufrimiento de los grupos más afectados por el conflicto armado interno, y buscaba sensibilizar a una sociedad criolla/limeña que ha sido históricamente indiferente a lo vivido en el interior del país. Sin embargo, es necesario reconocer que la sola presentación del sufrimiento humano sin el 
contexto sociopolítico que lo hizo/hace posible genera una empatía superficial. Si bien esta logra provocar tristeza y horror en el Otro, no permite que ese Otro espectador entienda de manera crítica la violencia, y por lo tanto la razón del sufrimiento humano.

Es importante considerar que, en contextos de posguerra como el que se vive en el Perú, la verdad del trauma aparece tanto en las experiencias del pueblo como en la economía moral de la sociedad contemporánea (cf. Fassin \& Rechtman, 2009: 276). La política de reparación, testimonio y prueba muestran modos prácticos de llevar el trauma al terreno de la acción. En cada caso lo central es crear empatía y también el reclamo que puede surgir de los derechos personales. Al tiempo que las «víctimas» aparecen en el contexto de un ethos de compasión, ellas son también una herramienta útil para exigir justicia.

Es fácil otorgar a ciertas personas el título de «víctimas» y ver cómo ellas se pueden mostrar a través del discurso. La clave del análisis no ha de estar en cuestionar este reclamo. Por el contrario, lo que necesitamos es entender que el lenguaje usado en los relatos no es neutro y, a pesar de ser un lenguaje universal en el Perú, este no intenta iluminar hechos concretos sobre actores y acciones significantes (cf. Fassin \& Rechtman, 2009: 280-281). Por más que las «víctimas» intenten ignorarlo, la persona siempre busca algún grado de acción: las «víctimas» tienen que enfrentarse a un sistema que los convierte en sujetos visibles.

Junto a esto, es importante señalar que los voceros del sufrimiento humano no logran borrar la jerarquía de poder y dominación en la cual se encuentran inmersos; tienen poder y lo utilizan para que las víctimas sean escuchadas. Sin embargo, estas víctimas no son escuchadas con su propia voz en la sociedad nacional, y ello les resta poder y retroalimenta la jerarquía entre intelectuales urbanos y campesinos quechuas. Por ello, a la vez que los voceros humanitarios denuncian, reproducen las estructuras de poder dominantes de la sociedad peruana.

Cuando enfatizamos que borrar el contexto histórico-político solo provoca una empatía superficial y temporal que no permite a la sociedad peruana entender las causas de la violencia y luchar contra ellas, resulta importante el elemento comparativo para ver qué ha sucedido en otras partes del mundo con la representación del sufrimiento humano causado por las guerras. En la actualidad, cuando el Museo de la Memoria, Tolerancia e Inclusión Social busca consolidar un discurso nacional, resulta importante reflexionar acerca de la historia que otros países han relatado en este tipo de lugares. Tanto en el museo del Apartheid en Sudáfrica como en el museo del Holocausto en EE. UU., el contexto histórico está ausente. En ambos a través de la empatía y la experiencia sensorial se presenta al visitante una historia de guerra, horror y sufrimiento. A pesar de ser muy distintos entre sí, estos museos tienen como objetivo final que el visitante desarrolle una empatía con el sufrimiento de las víctimas. La sobredimensión de lo sensorial en ambas propuestas genera una empatía real logrando que el visitante se ponga en los pies de los judíos perseguidos y en la exclusión de los sudafricanos negros durante el Apartheid. Sin embargo, ninguna de las exhibiciones se preocupa por mostrar las causas ni el contexto histórico-político que dio lugar a estos hechos, 
logrando borrar la historia de lo sucedido. Eso que se borra es esencial para entender y explicar por qué ocurrieron el Holocausto y el Apartheid, es decir la violencia. Estos museos contienen una narrativa de historia universal, donde la agencia de la masa es silenciada, donde el voluntarismo individual es contenido en un volumen atemporal (Crysler, 2006: 30).

Si pensamos en el caso peruano nos encontramos frente a una sociedad limeña que puede llegar a sentir empatía por la muerte y sufrimiento causados por el conflicto armado interno. Sin embargo, ello no provoca un real cuestionamiento de lo sucedido, y reproduce las distancias existentes entre Lima y el resto del país. Finalmente, el discurso que nos muestran las víctimas «puras» y guerras atemporales resulta más fácil de presentar y ser aceptado por la sociedad, que profundizar en los problemas sociales, políticos e históricos que provocan conflictos y violencia. Estancarnos en esto es negarnos a la posibilidad de entender en profundidad la guerra interna, la aún existencia de Sendero Luminoso en zonas como Chungui y el consiguiente compromiso con la justicia que deberíamos tomar.

\section{CHUNGUI Y CHAPI}

Chungui es un distrito ubicado en la parte sur de los Andes centrales del Perú (provincia de La Mar, Ayacucho). Este forma parte de los valles de los ríos Apurímac, Ene y Mantaro (VRAEM), una zona aún convulsionada por la violencia causada por parte de Sendero Luminoso y el narcotráfico ${ }^{5}$. Además es una región de difícil acceso, con una geografía agreste.

Los que no conocen esta zona la suelen llamar Oreja de Perro6, refiriéndose a todo el distrito. Sin embargo, el distrito está divido en dos comunidades campesinas: Chungui y Chapi. Aunque la población de la comunidad de Chungui llama Oreja de Perro a la comunidad de Chapi, los chapinos rara vez utilizan este término; por ello no será utilizado aquí. La población de Chungui busca diferenciarse de Chapi; esta diferencia normalmente pasa desapercibida para los foráneos, pero resulta crucial para entender las dinámicas internas del distrito, los conflictos y las diferencias que históricamente se han establecido en la zona.

La comunidad de Chungui ha sido una comunidad campesina autónoma desde el año 1920; mientras que la comunidad de Chapi fue una hacienda hasta 1974. Históricamente la relación entre Chungui y Chapi ha sido jerárquica y conflictiva. La comunidad de Chungui está orgullosa de ser históricamente una comunidad campesina independiente, lo que ha ayudado a sus miembros a producir un imaginario de superioridad al considerarse a sí mismos como agricultores «libres».

5 Véase Gorriti (2012).

6 Se hace una referencia directa al mapa de la región de Ayacucho, que es conocido localmente por tener forma de perro. Por su ubicación geográfica, el distrito de Chungui es considerado como «la oreja de perro».

7 Los chunguinos se definen como agricultores no como campesinos. 
Esto contrasta con la imagen de hacienda runa o gente de hacienda que tienen de aquellos que viven en Chapi, a quienes Ilaman campesinos pero que además los chunguinos describen como monolingües quechuas, analfabetos e ignorantes. La población de la comunidad de Chungui explica que la ignorancia (entendida como la carencia de una educación escolar) de los chapinos los ha hecho siempre proclives a ser explotados y engañados, primero por el hacendado y luego por Sendero Luminoso. Esto ha permitido que los comuneros de Chungui desarrollen relaciones de dominación y exclusión, relaciones que se repiten también en un nivel macro entre lo rural y lo urbano. La comunidad campesina de Chungui ha creado su propia identidad en contraposición a la de Chapi, proyectando una imagen de progreso como agricultores modernos, inteligentes, comerciantes prósperos y educados. Mucho de ello influenciado por la colonización temprana de la ceja de Selva en la zona.

Por su lado, los chapinos lamentan el monopolio de poder que ejerce Chungui en el distrito, pues esto solo desarrolla la mitad del distrito, y excluye a Chapi de servicios como electricidad y carreteras. Además los chapinos históricamente consideran a los chunguinos como egoístas, ya que no los consideran como parte del distrito.

El Censo Nacional del año 2007 señala que el distrito de Chungui tenía una población de 6195 personas, que la mayoría trabajaba en la agricultura y vivía en las zonas rurales del distrito (INEI, 2007). Durante mi trabajo de campo (20072009), el alza acelerada del precio de la hoja de coca hizo que se convirtiera en el producto más rentable del distrito: $11 \mathrm{~kg}$ de coca eran vendidos a \$ 30 dólares. Las cifras oficiales de la ONU señalan que a pesar de existir una reducción del cultivo de coca en la zona —en el año 2011 eran 62500 ha, mientras que en el año 2012 eran 60000 ha (UNODC \& Devida, 2013: 5)—, existe un incremento importante en el número de pozas de maceración. La ausencia de control policial directo en el distrito hace que la zona sea apta para el narcotráfico.

Los cambios que el distrito de Chungui ha logrado han surgido gracias a que este se convirtió en uno de los casos emblemáticos de la CVR. Es así como surge el discurso sobre la comunidad más afectada y olvidada durante el conflicto armado interno, que es usado constantemente por el alcalde de Chungui en cada encuentro que tiene con otros funcionarios del Estado. Sin embargo, el desarrollo solo se ha concentrado en la capital del distrito. Desde mayo del año 2008, el distrito ha sido visitado por grupos de Sendero Luminoso, quienes han contactado con autoridades y diversos pobladores para preguntarles sobre la situación política en el distrito. Estos senderistas dicen haber tomado distancia con Sendero Luminoso del año 1980, señalando que han aprendido de los errores del pasado. Además de Sendero Luminoso, el narcotráfico y la violencia que este provoca han sido utilizados para crear una imagen de Chungui como «tierra de nadie y de salvajes». Mientras trabajaba en los archivos de la Corte Superior de Huamanga, tanto abogados como el personal del poder judicial consideraban a Chungui como «zona liberada» donde los señores de la droga controlaban el distrito. Esta imagen circula en diversos ambientes incluyendo al Estado y las ONG. 
Cuando se etiqueta a Chungui como «tierra de nadie», se retroalimenta la idea de los Andes como un espacio habitado por gente salvaje, premoderna y de naturaleza violenta; una retórica que además pareciera estar justificada cuando se presenta esta región como una de las zonas que sufrió la violencia más cruel y sanguinaria durante el conflicto armado interno. Si bien parte de estas imágenes han surgido a partir de la publicación del Informe Final, estas se han reproducido subsecuentemente en artículos periodísticos, novelas y trabajos académicos que han contribuido a producir un discurso universal sobre el espacio ayacuchano, y en particular el distrito de Chungui y el sufrimiento vivido durante la guerra interna. El desafío es producir una crítica constructiva sobre las imágenes de «tierra de salvajes», que a la vez nos ayude a tomar consciencia de las consecuencias de la representación del sufrimiento que se han realizado sobre las víctimas del conflicto armado interno. Es decir, resulta importante reconocer que las víctimas se han visto obligadas a mostrar sus heridas y las peores humillaciones con el fin de obtener credibilidad en su relato, para producir compasión y empatía en la sociedad peruana.

Los discursos producidos a partir de la entrega del Informe Final sobre Chungui buscaron enfatizar la existencia de una región donde la vida siempre había estado regulada: primero por las haciendas, luego por Sendero Luminoso, y por las FF. OO.8 Sin embargo, esta también era una región con una larga tradición de rebeliones contra los abusos y la explotación de hacendados. Tanto Chungui como Chapi participaron en rebeliones en 1963, y luego apoyaron al Ejército de Liberación Nacional (ELN) en 19659. Asimismo, el informe que elaboramos para la CVR proporcionó datos importantes sobre las retiradas como estrategia de guerra por parte de Sendero Luminoso. Las retiradas consistían en movilizar a la población civil de la sierra a la selva alta o monte, para protegerla de las incursiones de las FF. OO. Una vez publicado el Informe Final, y por el grado de violencia desatado en esta región, Chungui y Chapi se convirtieron en casos emblemáticos de la CVR, consolidando desde entonces un discurso donde el distrito es «la comunidad más marginada y olvidada del Perú» (Degregori, 2009).

\section{3. «TIERRA DE NADIE Y DE SALVAJES»: LA REPRESENTACIÓN GRÁFICA DEL SUFRIMIENTO HUMANO}

La magnitud de la violencia vivida en el distrito era desconocida, y el equipo de la CVR recogió testimonios crueles y sanguinarios. Desde entonces las representaciones que surgieron sobre Chungui, en mi opinión, solo han contribuido a alimentar el imaginario ya existente de una comunidad donde la peor violencia puede ocurrir sin provocar protesta pública. Las representaciones

8 Véase la entrevista al Director Ejecutivo de la CVR (El Comercio, 10 de julio de 2005).

9 Cuando el ELN ingresó al distrito, lo hizo primero por Chungui donde tenía aliados comprometidos en liberar a sus hermanos yanaconas de la dominación del hacendado. Véase Koc-Menard (2011). 
que circularon, y que aún circulan, reducen esta comunidad a un escenario de guerra, un lugar por naturaleza violento, donde el sufrimiento de la población se representa a través de imágenes e historias mórbidas (Daniel, 1996). Es como si el distrito de Chungui se hubiese quedado atrapado en el manchay tiempo (tiempo del miedo) el que no permite narrar otras historias. Además, se produce una racialización importante, los cuerpos sufrientes que muchos testimonios y relatos muestran no son de los costeños, los criollos, los urbanos. Por el contrario, son los cuerpos andinos, asháninkas, pobres, «salvajes» y «marginales». Al encasillarlos en estas categorías, el Ilamado a la compasión y la empatía se hace muy fuerte. Este tipo de representaciones no dan espacio a maneras alternativas de entender la región, como por ejemplo el compromiso inicial con el proyecto de Sendero Luminoso ${ }^{10}$.

\section{1. Analizando Chungui. Violencia y trazos de memoria}

Edilberto Jiménez es un antropólogo ayacuchano, hijo de un conocido artesano de la región, de quien aprendió el arte de hacer retablos. En 1996, cuando trabajaba en una ONG en Ayacucho, llegó a Chungui por vez primera para trabajar en proyectos de comunicación y promoción cultural. Allí conoció a la población local y los diversos anexos del distrito. Esta experiencia le transmitió la magnitud de la violencia vivida por los chunguinos durante el conflicto armado interno. Durante años, Jiménez plasmó estos testimonios en dibujos. En el año 2009, Jiménez con el apoyo del Instituto de Estudios Peruanos (IEP) y de Carlos Iván Degregori publicó la segunda versión de un libro de testimonios gráficos recogidos a lo largo de su carrera. Jiménez explica su propio trabajo:

Cada dibujo tiene una historia... [En su forma final] algunos se hicieron en Chungui, otros en Ayacucho, Lima, los últimos en Tokio. Pero mis apuntes los hice al lado de los comuneros y ellos me indicaban cómo habían sucedido los hechos y yo hacía las anotaciones y así no llegaba a utilizar a veces la grabadora (Degregori, 2009: 22).

Degregori, quien escribió una parte importante del libro, considera que los que comenzaron como informantes de Jiménez terminaron siendo coautores de lo reseñado, al ilustrar, corregir y expresar el auténtico sentido de sus testimonios, volviendo más intenso y amplio el potencial de lo narrado a partir de insospechados

10 La práctica de mostrar imágenes de cuerpos sufrientes en su forma más descarnada pareciera ser una práctica común cuando se apela a la ayuda humanitaria. Tanto en Europa como en EE. UU., diversas ONG hacen este llamado mostrando niños y mujeres, usualmente africanos, desnutridos y al borde de la muerte. Esto busca producir en el espectador empatía y compasión que le permite actuar a través de la donación de dinero. En su gran mayoría las imágenes utilizadas son de la población africana, y sin negar que África sea uno de los continentes más pobres, estas imágenes de pobreza y sufrimiento se convierten en asociaciones cognitivas naturales con los «pobres africanos», retroalimentando los prejuicios existentes y dominantes. 
«espacios de visión»11 (Degregori, 2009: 22). Adicionalmente, afirma que el trabajo de Jiménez propone una manera diferente de conocer y «sentir» lo que sucedió en Chungui y en el Perú rural durante el conflicto armado. Es importante resaltar la manera innovadora de recoger testimonios a través del arte, de dibujos elaborados junto a las víctimas de las masacres. Es una técnica interesante que abre nuevas puertas a la representación del testimonio de guerra, y nos lleva a reflexionar acerca del rol de las víctimas y testigos.

Según Degregori, Chungui vivió un auténtico proceso de deshumanización, en el que fueron derribadas las barreras que separaban la cultura de la naturaleza y la barbarie de la civilización (Degregori, 2009: 22). Aunque existió una colaboración colectiva en la producción de dibujos de Jiménez, al final todo fue reconocido y citado como un trabajo realizado por el antropólogo artista. Esto no es extraño, pues como cualquier etnografía los datos utilizados provienen de la voluntad de los informantes para compartir sus historias, pero como investigadores acabamos modelando una representación cuya autoría es nuestra y no del informante. Si bien es importante reconocer la originalidad de la técnica de Jiménez, también es necesario admitir la relación jerárquica que existe entre Jiménez y los chunguinos. Es decir, Jiménez y Degregori se convierten en voceros humanitarios, en testigos del sufrimiento padecido en Chungui. Ello no permite que sea la población de estas comunidades quienes narren directamente sus testimonios. Jiménez se convierte en un mediador que finalmente resalta lo que a él le parece más importante.

Más adelante, Degregori señala:

Las comunidades fueron desarticuladas, sus autoridades desconocidas y en muchos casos asesinadas. Las familias fueron quebradas sistemáticamente, dividiendo padres de hijos, imponiéndoles incluso nuevos nombres a los pueblos y a la gente. Los individuos fueron sometidos para controlar hasta sus sentimientos más íntimos. En el colmo del delirio, estaba prohibido entristecerse aun en medio de las mayores desgracias; y prohibido llorar, incluso en el momento de presenciar el asesinato de familiares, vecinos y amigos (Degregori, 2009: 22).

Degregori considera que la violencia entre 1984 y 1987 es equiparable a un potlatch humano. Además explica que para los comuneros que se organizaron en las rondas campesinas más agresivas, los motores de la violencia fueron la fragmentación de la sociedad rural y específicamente la de las comunidades, así como el pragmatismo en un estado límite convertido en una estrategia de supervivencia o depredación (Degregori, 2009: 24). En otras palabras, la violencia del día a día se incorporó a la vida diaria como estrategia de supervivencia.

En contraste con lo que Degregori y otros señalan en el trabajo antes citado, Chungui constituye un relato más de la guerra entre los proporcionados por la

11 Degregori usa «espacios de visión» jugando con el concepto de lugares de enunciación. A pesar de ello no es claro, pues podría decirse que la colaboración de los comuneros de Chungui en los dibujos de Jiménez no corresponden ni a un lugar de visión ni a un determinado lugar de enunciación. 
CVR. La violencia aparece particularmente cruel e irracional debido a las retiradas y al desconocimiento que se tenía de la magnitud de la violencia vivida en este distrito «desconocido». Durante los años del conflicto armado interno, la gente fue cambiando de bando, según presiones y conveniencias. El motivo principal para las primeras ejecuciones de Sendero Luminoso fueron las traiciones a los ideales del partido. Primero, llegaban miembros de las FF. OO. y obligaban a la población a acusar a los seguidores de Sendero para ejecutarlos. Esta persecución se suspendió temporalmente cuando los pobladores que permanecieron en su comunidad fueron organizados en retiradas. Las retiradas eran el método empleado por Sendero Luminoso en el distrito de Chungui para que la población huyera de su pueblo — por voluntad propia y coaccionados- hacia el monte. Allí eran organizados y controlados directamente por el partido ${ }^{12}$.

Entre 1983 y 1987 centenares de familias de Chapi vivieron en retiradas. Para Sendero Luminoso, la gente organizada en estas pasó a constituir la masa que conformaba la base real del Nuevo gobierno de nueva democracia que proponían. Al inicio, Sendero Luminoso trataba a todos de forma igualitaria. Para algunos, esto era la comunidad igualitaria donde no existían diferencias. Todos debían trabajar para beneficio del grupo, no existían individualismos ni explotación. Las antiguas diferencias socioeconómicas habían sido una de las fuentes de conflictos internos después de la Reforma Agraria; y Sendero Luminoso se encargó de borrarlas, al menos temporalmente.

Cuando Sendero Luminoso iba perdiendo la guerra y la comida escaseaba, la violencia se fue incrementando. Las visitas de control de los mandos senderistas eran más esporádicas, lo que dio más autonomía y poder a los mandos locales sobre la masa. En el año 2002, la gente señalaba que la mayor parte de las violaciones a los Derechos Humanos provenían de estos mandos, pues castigaban y ejecutaban a la masa. Además, los conflictos personales y familiares se convirtieron en pretextos para ejecutar gente en nombre del partido.

Yo estaba preocupada porque los compañeros llamaban a asamblea y los que no asistían iban a morir. De mucho miedo fui a la asamblea. A mi esposo y a mi papá, como no fueron les dieron mil látigos hasta que se enfermen. Luego cocinábamos juntos porque cuando nos encontraban cocinando individualmente se molestaban y nos castigaban (CVR.BDII-P608, entrevista en profundidad, Huallhua. Mujer de 35 años).

La vida se iba tornando más violenta y peligrosa. El ideal de vida comunitaria estaba amenazado por el continuo patrullaje de las FF. OO. y los ronderos, por la escasez de alimentos y la desnutrición de la masa. Los campamentos se trasladaban continuamente de un lugar a otro, y muchas veces los últimos en

12 A diferencia de otras regiones ayacuchanas donde se produjo control político por parte de Sendero Luminoso, las retiradas tenían una organización y distribución de tierras distintas. Entre otras razones, está el tiempo de duración de los campamentos que se fueron acortando por la contraofensiva de las rondas y militares. 
escapar eran las mujeres y los niños, quienes eran capturados y ejecutados por las patrullas13. Hasta 1987 la población de las retiradas creía firmemente que todo intento de fuga del dominio de Sendero Luminoso y aproximación a los militares era una sentencia de muerte.

Las retiradas y la extrema violencia vivida por la población del distrito de Chungui fue lo que convirtió este en un caso emblemático para la CVR. Siguiendo esta línea, el libro de Jiménez se concentra en ofrecer varios textos y descripciones que relatan las retiradas y el sufrimiento padecido en ellas. Degregori señala:

Las retiradas se convirtieron en un infierno, no sólo para las masas obligadas a vivir y más bien morir allí, en muchos casos como en campos de concentración, sino para los propios mandos senderistas. Es que Sendero Luminoso partió de un conjunto de premisas equivocadas. La primera, conforme se prolongara el conflicto armado, el tiempo correría a su favor. Inspirados en la estrategia de «guerra popular prolongada» de Mao Zedong, apostaron al lento desgaste del viejo estado [...] La base de esta premisa era considerar que el campesinado, especialmente el campesinado pobre, era el aliado natural de Sendero Luminoso, y que por lo tanto permanecería fiel al partido a lo largo de todo ese complicado y sangriento proceso (Degregori, 2009: 25-26).

Degregori interpreta de este modo lo que el Informe Final había dicho seis años antes: que Sendero Luminoso no supo comprender la heterogeneidad de Chungui ni la importancia de la cultura local, no solo en la producción de ideas sino también en su organización social y política. Además, añade que Sendero Luminoso no reconoció que el pueblo de Chungui tenía sus propios intereses ni que eran sujetos políticos con agencia propia. Aunque el autor reconoce que existía una auténtica capacidad de acción, la cual condujo a los chunguinos a aceptar o rechazar la ideología de Sendero Luminoso (Degregori, 2009: 26-27), su análisis queda en la descripción y no permite ir más allá en la reflexión. Esto hubiese permitido incluir las distintas formas de resistencia que la población utilizó y aún utiliza, como la lucha diaria contra los abusos de las FF. OO. y el enfrentamiento de las autoridades frente a Sendero Luminoso.

Los siguientes ensayos en este libro incluyen descripciones del distrito de Chungui, siendo el corazón del libro los gráficos sobre las retiradas y la violencia ejercida por las FF. OO., las rondas y Sendero Luminoso. Aunque las narraciones originales fueron realizadas en quechua, Jiménez las tradujo al castellano sin distinguir las que procedían de la comunidad de Chungui y las de Chapi. Esto constituye un problema puesto que, por razones históricas, es importante reconocer la diferencia política y la fragmentación interna entre ambas comunidades para identificar las características particulares de la guerra y sus distintos grados de violencia en ambas comunidades. El conflicto armado interno no puede ser entendido como

13 Esto se ha confirmado con la presencia de un alto número de niños y mujeres, en las fosas que se han empezado a exhumar en el distrito de Chungui (Mejía, 2013). 
un fenómeno homogéneo que afectó a todos de la misma manera. Las familias adineradas — los «notables»— de Chungui fueron los primeros en abandonar el distrito; mientras tanto, muchos jóvenes fueron adoctrinados en el colegio y participaron en el proyecto de Sendero Luminoso. Hubo gente que se vio obligada a vivir en las retiradas, pero hubo también un grupo significativo que se unió al partido porque creía en su discurso de justicia e igualdad. Si bien esto no borra la realidad del sufrimiento y la muerte como fenómenos cotidianos durante el conflicto armado interno, asumir los testimonios que presenta Jiménez como si fueran una evidencia absolutamente transparente de la guerra condiciona la comprensión real del fenómeno. En lugar de argumentar, las citas que contienen los ensayos de Jiménez se constituyen per se en argumentos únicos de lo sufrido en Chungui. El vocero humanitario habla de las retiradas a través de sus dibujos y su interpretación de los hechos. Jiménez está dentro de cada uno de los dibujos y de los relatos que el libro recoge, el rol y la presencia del antropólogo no pueden eliminarse. Estos no son dibujos o relatos escritos por los propios chunguinos, estos le pertenecen a Jiménez y ello es esencial reconocerlo. La estructura jerárquica de poder y dominación en la que se encuentran inmersos Jiménez y Degregori en relación con los chunguinos, provoca que los académicos se conviertan en voceros humanitarios de lo que es representado como víctima pasiva, monolingüe quechua e ignorante, cuya voz no tiene el poder de ser escuchada. Así, se perpetúa la jerarquía tradicional de una clase intelectual que tiene la tradición de hablar por el otro.

Cuando Degregori sustenta que Sendero Luminoso no reconoció al pueblo como un sujeto con agencia, es importante preguntarse si, como académicos, no estamos también negándole a la población rural su rol como sujetos políticos con poder de decisión, acción y voz propia. Este libro es un alegato convincente sobre la violencia y el sufrimiento producido por el conflicto armado interno. Sin embargo, como sucede con todas las narraciones, estas no deberían ser tomadas como verdades absolutas, pues están condicionadas por determinado contexto histórico y una retórica que llama al lector a sensibilizarse y establecer una relación de empatía ante el sufrimiento. A pesar de ello, es necesario preguntarnos sobre la actitud que se debe asumir para evitar reproducir las relaciones tradicionales de dominación racial y espacial entre criollos/mestizos y la población rural andina.

Este es un libro que relata a través de imágenes la tortura, la violencia y el sufrimiento padecido en Ayacucho durante el conflicto armado interno. Aunque el libro de Jiménez contiene el ensayo de Degregori (y otros) que tienen la intención de dar un enfoque académico sobre la región, finalmente este es un libro con ilustraciones y no un trabajo analítico. La descripción del distrito es completa, como también lo es la de la vida transcurrida durante los años de la guerra; no obstante, no se trata de una historia diferente a la que fue presentada por el Informe Final. Es un libro cuyo corazón son los dibujos de Jiménez y el sufrimiento humano que ellos evocan, un llamado a la empatía y compasión del lector. Como sucede en otras sociedades de posguerra, los chunguinos han aprendido que, cuanto más sufrimiento y dolor exhiban, mayor es la posibilidad 
de recibir ayuda y captar la atención por parte del Estado y otras instituciones. Sin embargo, ello no debería ser interpretado como que la población realmente se considera sufrida o sin agencia política. El uso de determinados discursos sociales por parte de los chunguinos en las relaciones que establecen con el Estado y la sociedad, no quiere decir que esta población se considere a sí misma pasiva e ignorante14. Además, hoy en día los testimonios que los chunguinos ofrecen sobre el conflicto armado son distintos a los que recogimos hace diez años; los han pulido eliminando cualquier acción y creencia política que hayan podido tener en la década de 1980. Ello simplifica su posición como víctimas «puras», es decir sujetos sobre los cuales no puede cuestionarse nada.

En este sentido, Da Silva Catela sugiere que es importante resistir frente a las nociones de pureza de las víctimas, pues ello no lleva a la comprensión ni a la explicación de la situación límite de la experiencia vivida durante el conflicto armado interno, en otras palabras, no incluye lo ambiguo, lo impuro ni lo borroso. Esto contradice la demanda de muchas víctimas y familiares por mantener una narrativa con categorías polares y bien definidas: héroe/colaborador, víctima/ perpetrador, etc. Además, ello muestra que el pasado está en disputa, y enfatiza la importancia de reconocer la complejidad del proceso vivido durante el conflicto. Asimismo, esta idea demanda desarmar discursos gloriosos y luchar contra la inhumanidad del otro. El peligro de una presentación polarizada como algunos sectores sugieren, es que con ello no se dice nada y no se logra comprender la complejidad de la realidad vivida (Da Silva Catela, 2013: 12).

A partir de la CVR, Degregori y otros estudiosos parecieran haberse convencido de que mostrar el sufrimiento causado por la violencia es un acto de responsabilidad política que permite a la sociedad peruana enterarse de lo sucedido en el conflicto armado interno. En este sentido señala:

El Perú y los peruanos tenemos una deuda pendiente con Chungui. Este libro es una forma de amortizarla a través de la etnografía y el arte. [...] como estas páginas han demostrado, fue tan solo el principio de una larga y ardua tarea que debe ser continuada, y mejorada en la búsqueda de una verdad perfectible y purificadora, que nos abra las puertas de la justicia, la reparación y la reconciliación del país (Degregori, 2009: 35).

La deuda contraída por la sociedad peruana con Chungui es la misma que se debe a los centenares de comunidades andinas y amazónicas, así como a las miles de personas que padecieron la guerra interna y que no han tenido un libro o una ONG que recuerde a las elites urbanas y a los académicos que ellas siguen reclamando justicia. Si bien este libro representa un merecido reconocimiento de lo que la población padeció en Chungui, no pareciera ser la única manera de honrar la deuda que la sociedad peruana tiene con ellos. El libro pretende, sin dudas, compensar de alguna manera a estas comunidades, pero vale la pena preguntarnos cuál es la compensación y reparación que los chunguinos consideran

14 Para una discusión más extensa, véase Koc-Menard (2011). 
apropiada. Mientras las relaciones de poder y dominación entre académicos y campesinos se reproduzcan bajo el velo de las denuncias de sufrimiento por voceros humanitarios, poco es lo que realmente se ha logrado para resarcir a las comunidades afectadas por el conflicto armado interno.

Este libro se asemeja mucho a la tarea de la CVR: era un proyecto político necesario, pero ello no significaba que iba a beneficiar a la población rural. De la misma manera, este libro no beneficia necesariamente a los chunguinos, pero intenta decir que es el inicio de pago de la deuda. Nuestra redención moral como investigadores e intelectuales no corresponde por sí misma con una mejora significativa en la vida de las comunidades andinas. Más bien deberíamos preguntarnos quién se beneficia de esta tarea y por qué sería tan importante llevarla a cabo.

Hoy en día, las «víctimas» cuestionan y denuncian la manera cómo su sufrimiento y dolor han sido convertidos en fuente de ingresos para las ONG y los artistas, cómo estas han sacado provecho de sus vidas y su sufrimiento. Muchas personas en diversas comunidades se sienten utilizadas por quienes antes consideraban sus aliados: las ONG. Como comentó el Director de la Comisión de Derechos Humanos (Comisedh15):

Me he encontrado en reuniones con personas que reclaman que las ONG y otras instituciones se vuelven millonarios con su sufrimiento. Creen que por hacer una película, un documental... se viaja, y se gana concursos... y la gente cree que nos hemos llenado de dinero... se imaginan miles de dólares y reclaman: «Y nosotros seguimos igual y peor. En cambio ustedes... se llenan los bolsillos».

En el caso del distrito de Chungui esta historia no difiere mucho de la cita anterior. Algunos comuneros de Chapi imaginan que Jiménez se ha vuelto famoso por el libro que publicó con el IEP, y a pesar de haberlo presentado en Chungui en octubre de 2009, la población de Chapi siente que su dolor ha sido utilizado para el beneficio de Jiménez, a quien imaginan viajando y recibiendo dinero, mientras ellos sienten que siguen viviendo una situación de olvido y marginación. Es decir, la vida para el distrito de Chungui, y particularmente para la comunidad de Chapi, ha cambiado muy poco y en algunas zonas casi nada. Si bien no es un sentimiento que pueda generalizarse, la desconfianza de que otros se vuelven «ricos y famosos» con sus historias de dolor genera rabia y resentimiento entre la población que se siente excluida de los beneficios que imaginan estas producciones generan. Ello les hace constatar que las jerarquías de poder y raza entre ellos, como campesinos, y los académicos se mantienen y retroalimentan.

\section{REFLEXIONES FINALES}

El libro ilustrado analizado en este texto, sin duda tiene «buena intención», pues pretende que se tome conciencia de los sufrimientos padecidos durante

15 Entrevista realizada a Pablo Rojas (Lima, 2009). 
el conflicto armado interno. Si bien su objetivo era denunciar la violencia y el sufrimiento vivido en Chungui, este ha producido, reproducido y diseminado imágenes del sufrimiento de víctimas ahistóricas. En conclusión, los chunguinos, así como muchas comunidades quechuas, parecieran haberse vuelto visibles para el Estado porque son considerados como «víctimas» que experimentaron lo peor del conflicto armado interno. Esto no ha modificado el hecho de que, en el proceso de ser etiquetados como «víctimas», estos comuneros que viven en zonas rurales sean considerados ignorantes, violentos y carentes de una voz propia. Hace diez años la CVR no podía producir un discurso que reconociera a las víctimas de la violencia como sujetos políticos, pues ello significaba reconocer que habían participado con Sendero Luminoso. La imagen de «víctimas puras» permitía transmitir un mensaje claro sobre el sufrimiento y la magnitud de la violencia, simplificando una guerra llena de matices para que sea escuchada por los sectores más conservadores de la sociedad peruana. Sin embargo, en la actualidad es importante reconocer a estas «víctimas de la violencia» como importantes actores políticos, que pueden manipular las formas de representación y discursos producidos y empleados por los académicos, las ONG y el Estado. Es decir, «las víctimas» no son simples receptores pasivos de lo hecho por Sendero Luminoso y el Estado. En lugar de incluir un análisis de lo que los pobladores del distrito de Chungui están haciendo como actores políticos (como la resistencia organizada a las incursiones de Sendero Luminoso durante el conflicto armado interno y en la actualidad), a diez años del Informe Final seguimos reproduciendo el mismo discurso de víctimas «puras» y cuerpos sufrientes atemporales. Hoy en día, el reto debe ser regresar la agencia a los pobladores rurales para entender que esta fue una guerra más complicada que la de una población cercada entre dos fuegos.

En este contexto, los voceros humanitarios (Jiménez, Degregori y otros) ocupan el lugar de los testigos directos, editando — consciente o inconscientementela información testimonial obtenida (cf. Fassin \& Rechtman, 2009: 193). Estos testigos suplentes publican solamente los elementos que juzgan importantes, lo que llamará la atención inmediata y el compromiso de la sociedad nacional. En el caso de Chungui se elimina la distinción borrosa entre víctimas y victimarios, la participación de la población en Sendero Luminoso, y se opta por mostrar solo sufrimiento y dolor.

«Al margen del Estado» o «comunidad marginal» son expresiones rara vez cuestionadas y que, sin embargo, se utilizan continuamente como si fueran verdades incuestionables y retrataran con exactitud a las comunidades andinas en el Perú. En el discurso público, nada que se refiera a ellos contiene un verbo activo, un verbo de acción; todas las descripciones sobre ellos se hacen en voz pasiva. Esto sucede frecuentemente con la plena participación de las «víctimas» a quienes les conviene presentarse sin agencia para ser reconocidas como inocentes por el Estado y poder recibir compensaciones económicas. Y aquí radica precisamente el problema: son etiquetados como «víctimas» y sus historias se ven reducidas a relatos sufrientes y de dolor diseminados por el Estado, las ONG y los académicos. 
Se quedan atrapados en una identidad y actitudes de victimización, que hoy en día se han convertido en un capital y una estrategia de visibilidad frente al Estado.

Finalmente, relatos como los de Chungui intentan narrar una historia con la que todo peruano debería sentir empatía y tristeza. Pero hoy en día ¿̇e qué nos sirve un discurso que crea empatía y nos presenta víctimas y una guerra sin temporalidad, si no se cuestionan las razones por la cuales el conflicto armado surgió y el contexto histórico que permitió esta violencia? Contextualizando el sufrimiento y el dolor vivido durante el conflicto armado interno con la historia que provocó este dolor permitiría visualizar, como individuos y sociedad, las razones por las cuales surgió la guerra y luchar contra las causas que la hicieron y la continúan haciendo posible.

\section{Referencias citadas}

COMISIÓN DE LA VERDAD Y RECONCILIACIÓN (CVR), 2003 - Informe Final. Volumen 5: Historias representativas de la violencia. Los casos de Chungui y Oreja de Perro: 85-119.

CRYSLER, C., 2006 - Violence and Empathy: National Museums and the Spectacle of Society. Traditional Dwellings and Settlements Review, 17, n. ${ }^{\circ}$ 2: 19-38.

DA SILVA CATELA, L., 2013 - Esas Memorias... ¿Nos Pertenecen? Riesgos, debates y conflictos en los sitios de memoria en torno a la estatización y los proyectos públicos sobre los usos del pasado reciente. Seminario Internacional Dictaduras Militares en enfoque comparado; Belo Horizonte.

DANIEL, E. V., 1996 - Charred Lullabies: Chapters in an Anthropography of Violence, xii + 252 pp.; Princeton: Princeton University Press.

DEGREGORI, C. I., 2009 - Edilberto Jiménez. Una temporada en el infierno. In: Chungui. Violencia y trazos de memoria (E. Jiménez, ed.): 19-35; Lima: Instituto de Estudios Peruanos, Comisedh, DED, ZFD.

FASSIN, D. \& RECHTMAN, R., 2009 - The Empire of Trauma. An Inquiry into the Conditions of victimhood, xii +305 pp.; Princeton: Princeton University Press.

GORRITI, G., 2012 - El Epílogo De Un Secuestro. Caretas, n. ${ }^{\circ}$ 2231: 22-23.

INSTITUTO NACIONAL DE ESTADÍSTICA E INFORMÁTICA (INEI), 2007 - Censos de Población y Vivienda 2007. Disponible en: http://ineidw.inei.gob.pe/ineidw/\#

JIMÉNEZ, E., 2009 - Chungui. Violencia y trazos de memoria, 416 pp.; Lima: Instituto de Estudios Peruanos, Comisedh, DED, ZFD.

KOC-MENARD, N., 2011 - Social Mediation and Social Analysis: The Discourse of Marginality in the Theatre of War. PhD. diss., University of Michigan.

MEHL, D., 1996 - La Télévision de l'intimité, 253 pp.; París: Seuil.

MEJÍA, M., 2013 - Horror: 19 fosas conservan los restos de 56 civiles en las alturas de Chungui. La República (3 de diciembre de 2013): 2-3.

UNODC \& DEVIDA, 2013 - Perú. Monitoreo de cultivo de coca 2012, 77 pp.; Lima. 